\title{
Las desigualdades educativas en Mendoza en la primera mitad del siglo $\mathrm{XX}^{*}$
}

\author{
Juan Manuel Cerdá
}

\begin{abstract}
Afiliado institucionalmente al Consejo Nacional de Investigaciones Científicas y Técnicas-CONICET (Argentina). Correo electrónico: jmcerda@unq.edu.ar. El autor es doctor en Ciencias Sociales y Humanidades de la Universidad Nacional de Quilmes (Argentina). Entre sus publicaciones recientes tenemos: en coautoría "Brechas del bienestar: el problema de la vivienda rural argentina entre las décadas de 1930 y 1950". Revista Trashumante No 10 (2017) y en coautoría "Intervención estatal y agroindustria vitivinícola: el caso de la Junta Reguladora de Vinos”. H-Industria, Revista de historia de la industria, los servicios y las empresas en América Latina, Año 10, $\mathrm{N}^{\circ} 18$, (2016). Entre sus temas de interés están vitivinicultura, pobreza rural y condiciones de vida en Argentina y América Latina.
\end{abstract}

Recibido: 26 de agosto de 2016

Aprobado: 26 de enero de 2017

Modificado: 5 de marzo de 2017

Artículo de investigación científica

DOI: http://dx.doi.org/10.15648/hc.31.2017.5

* $\quad$ Este artículo forma parte del proyecto: "Un estudio multidimensional en torno a la vitivinicultura mendocina" financiado por el Consejo Nacional de Investigaciones Científicas y Técnicas - CONICET (Argentina).

Esta publicación está bajo una licencia Creative Commons Reconocimiento-NoComercial 4.0 


\title{
Las desigualdades educativas en Mendoza en la primera mitad del siglo XX
}

\section{Resumen}

Este trabajo se basa en el análisis de los Censos Nacionales de Población y Educativos, informes institucionales y en los informes de algunos expertos que fueron funcionarios en la provincia de Mendoza. En él, la educación es vista como indicador del grado de desarrollo alcanzado por la sociedad mendocina en la primera mitad del siglo XX. Se eligió esta provincia por sus características económicas y porque en ella los datos permiten hacer un análisis desagregado a nivel local. A partir del estudio de información cuantitativa y cualitativa fue posible identificar la existencia de importantes desigualdades de oportunidades educativas tanto por género, como entre las regiones que componen la provincia. En particular, se evidenciaron las mayores dificultades de las mujeres con relación a los hombres para completar o acceder a la educación básica, así como las diferencias entre las áreas urbanas y rurales. Asimismo, se observó una elevada tasa de abandono escolar desde temprana edad en áreas rurales, casi siempre por las necesidades económicas de sus familias.

Palabras clave: educación, analfabetismo, desarrollo económico, Mendoza, Argentina.

\section{Inequalities in Education in Mendoza in the first half of the twentieth century}

\begin{abstract}
This paper is based on the analysis of National Population and Educational Censuses, institutional reports and some experts' accounts, who were officials of Mendoza Province. In here, education is seen as an indicator of the level of development reached by the society in Mendoza in the first half of the twentieth century. This province was chosen because of its economic characteristics and the obtained data, which could lead to a disaggregated local analysis. From the study of qualitative and quantitative data was possible to identify the existance of major inequalities in educational opportunities in gender as well as in the regions that make part of the province. In particular, major difficulties were evident in women, comparing to men, to complete or have access to basic education, as well as the differences between the urban and rural áreas. In addition, a high rate of school truancy at early ages in rural áreas was observed, almost always due to economic needs in their families
\end{abstract}

Keywords: education, illiteracy, economic development, Mendoza, Argentina 


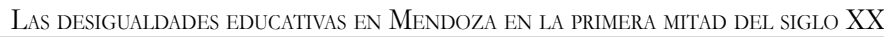

As desigualdades educacionais em Mendoza na primeira metade do século XX

\section{Resumo}

Este trabalho se baseia em analises dos Censos Nacionais de População e Educativos, relatórios institucionais e em relatórios de alguns especialistas que foram funcionários na província de Mendoza. Nele, a Educação em vista como indicador de grau de desenvolvimento alcançado pela Sociedade de Mendoza na primeira metade do século XX. Selecionou-se esta província por suas características econômicas e por que nela os dados permitem uma análise descentralizada a nivel local. A partir do estudo de informação quantitativa qualitativa, foi possível identificar a existência de importantes desigualdades de oportunidades educativas tanto por gênero, como entre as regiões que compõe a província. Em particular se evidenciaram as maiores dificuldades das mulheres em relação aos hombres para completar ou ter acesso à educação básica, assim como as diferenças entre as áreas urbanas e rurais. Também se observou uma elevada taxa de abandono escolar entre as crianças nas áreas rurais, quase sempre pelas necessidades econômicas de suas famílias.

Palavras-chaves: educação, analfabetismo, desenvolvimento econômico, Mendoza, Argentina.

\section{Les inégalités éducatives à Mendoza dans la première moitié du $\mathrm{XX}^{\mathrm{e}}$ siècle}

\section{Résumé}

Ce travail se fonde sur l'analyse des Recensements Nationaux de Population et Éducatifs, sur des rapports institutionnels et sur des rapports de quelques experts qui furent des fonctionnaires dans la province de Mendoza. Dans cet article, l'éducation est vue comme un indicateur du niveau de développement atteint par la société de la province de Mendoza dans la première moitié du $\mathrm{XX}^{\mathrm{e}}$ siècle. On a choisi cette province par ses caractéristiques économiques et parce que dans son cas les données permettent de faire une analyse détaillée au niveau local. À partir de cette étude d'information quantitative et qualitative, on a pu identifier l'existence d'importantes inégalités d'accès à l'éducation tant par genre que parmi les régions qui composent la province. On a notamment mis en évidence les plus grosses difficultés des femmes par rapport aux hommes pour compléter ou accéder à l'éducation basique, ainsi que les différences entre les aires urbaines et rurales. De même, on a remarqué un taux élevé de désertion scolaire dès le plus jeune âge dans les zones rurales, presque toujours associé aux mauvaises conditions économiques de leurs familles.

Mots clés: éducation, analphabétisme, développement économique, Mendoza, Argentina. 


\section{INTRODUCCIÓN}

La educación pública y gratuita fue una las primeras políticas desarrolladas en la Argentina como parte de la construcción del Estado Nacional a finales del siglo XIX. El analfabetismo ha sido uno de los problemas sociales que más ha preocupado al Estado argentino hasta el punto de que la organización y el sostenimiento de la instrucción primaria era -junto con la organización de justicia y el régimen municipal- uno de los tres requisitos que la Constitución Nacional imponía a las provincias para que el gobierno federal las reconociera en libre y pleno goce de sus instituciones (Art. 5). Esta idea se fortaleció con la promulgación de la Ley 1.420 en 1884 , la cual tenía como propósito la implementación de un sistema educativo obligatorio, gratuito, gradual y conforme a los preceptos de la higiene (Art. 2). La legislación garantizaba el derecho a la educación a todos los individuos y apelaba a la responsabilidad de los padres, los cuales serían penalizados si no cumplían con la obligatoriedad de mandar a sus hijos a la escuela (Arts. 17 y 44, inciso $8^{\circ}$ ). Sin embargo, el proceso de inclusión a la escolarización primaria recién se universalizó a mediados del siglo pasado pero, como se mostrará, de manera desigual tanto a nivel del territorio como también entre sexos. En particular, el grado de escolarización alcanzado por los niños estaba fuertemente relacionado con las posibilidades económicas de sus familias así como también con la disponibilidad de infraestructura educativa.

Este trabajo se centra en el análisis de las desigualdades en los logros educativos y sus factores asociados en la provincia de Mendoza. En particular, se busca analizar en profundidad en qué medida estos fueron alcanzados en dicho territorio. Para ello se parte de la hipótesis de que la educación es un bien deseado por todos los individuos de una forma más o menos homogénea, más allá de las posibilidades que cada uno de ellos tenga para acceder a ella y del nivel alcanzado en cada período histórico. Así, se entiende que la educación fue un bien requerido por los sectores subalternos que veían en ella una forma de ascenso social para sus hijos. Esto ha quedado reflejado en la dramaturgia costumbrista de comienzos del siglo XX como, por ejemplo, en M’bijo el dotor de Florencio Sánchez.

Sin embargo, más allá del deseo de los individuos, existieron condiciones que incidieron en el acceso efectivo a la educación y, por lo tanto, en 
los niveles de analfabetismo. Estos factores se vincularon, tanto con las políticas públicas que desde el Estado se promovieron como con la demanda de educación que la sociedad hizo. Respecto de lo primero, puede mencionarse la existencia de establecimientos públicos cercanos al lugar donde el niño vive, la posibilidad de acceder al material didáctico para el aprendizaje, la disponibilidad de maestros, entre muchos otros. Respecto de los factores que incidieron sobre la demanda de educación es posible mencionar las condiciones materiales de la familia que permitieron (o no) la asistencia a la escuela y, en cierta medida, los requerimientos de selección en el mercado de trabajo, que pudieron condicionar las elecciones del tipo o grado de educación que debía alcanzar un individuo. Así, el nivel educativo alcanzado por las personas determinaría las posibilidades de acceso a un puesto de trabajo y, a su vez, la posibilidad de un mayor desarrollo individual o ascenso social.

En este sentido, el nivel de analfabetismo promedio también es un indicador aproximado de los requerimientos mínimos del proceso productivo o del mercado de trabajo en un momento histórico determinado. Así, la educación estaría vinculada a las construcciones sociales a las que los individuos deben someterse para mantenerse dentro de un sistema de reglas y costumbres aceptadas, las que, a su vez, dan forma a sus preferencias. En este sentido, los requerimientos de ciertos conocimientos por parte del mercado de trabajo pudieron actuar (o no) como incentivo del incremento educativo de una sociedad. En sociedades predominantemente rurales estos requerimientos estarían asociados a prácticas culturales asociadas a la producción primaria mientras que en las sociedades urbanas los requerimientos educativos formales aumentarían debido al tipo de actividad que allí predomina: comercio, industria y servicios.

En este marco general, nos interesa analizar la evolución de la educación en la provincia de Mendoza durante la primera mitad del siglo XX, poniendo especial atención a la década de 1930. Durante todo el período estudiado, Mendoza tenía los valores cercanos a la media nacional, pero con niveles que se diferenciaban entre un departamento y otro ${ }^{1}$. Esto per-

1 Sin embargo, los resultados obtenidos están enmarcados en un proceso más general que ocurrió a nivel nacional, caracterizado por la disminución progresiva e ininterrumpida de los niveles de analfabetismo desde la implementación de la Ley 1.420 hasta mediados del siglo XX. 
mite analizar la evolución de las diferentes variables, así como también los efectos que tuvieron las políticas públicas a escala local.

Por otro lado, Mendoza se encuentra ubicada en el centro-oeste de la República Argentina y cuenta con la particularidad de concentrar en tres oasis productivos (el $3 \%$ de su territorio) el total de la población y de su producción, convirtiéndose las tierras irrigadas en regiones socio-productivas complejas. Estos oasis productivos se dividen en tres: el Oasis norte, que comprende las cuencas del río Mendoza y Tunuyán, el Oasis Sur irrigado por el río Diamante y Atuel y el Oasis Centro-Oeste (más conocido como Valle de Uco) que está alimentado por las aguas del río Tunuyán (Ver imagen 1).

\section{Imagen 1}

Mapa de las regiones de la Provincia de Mendoza

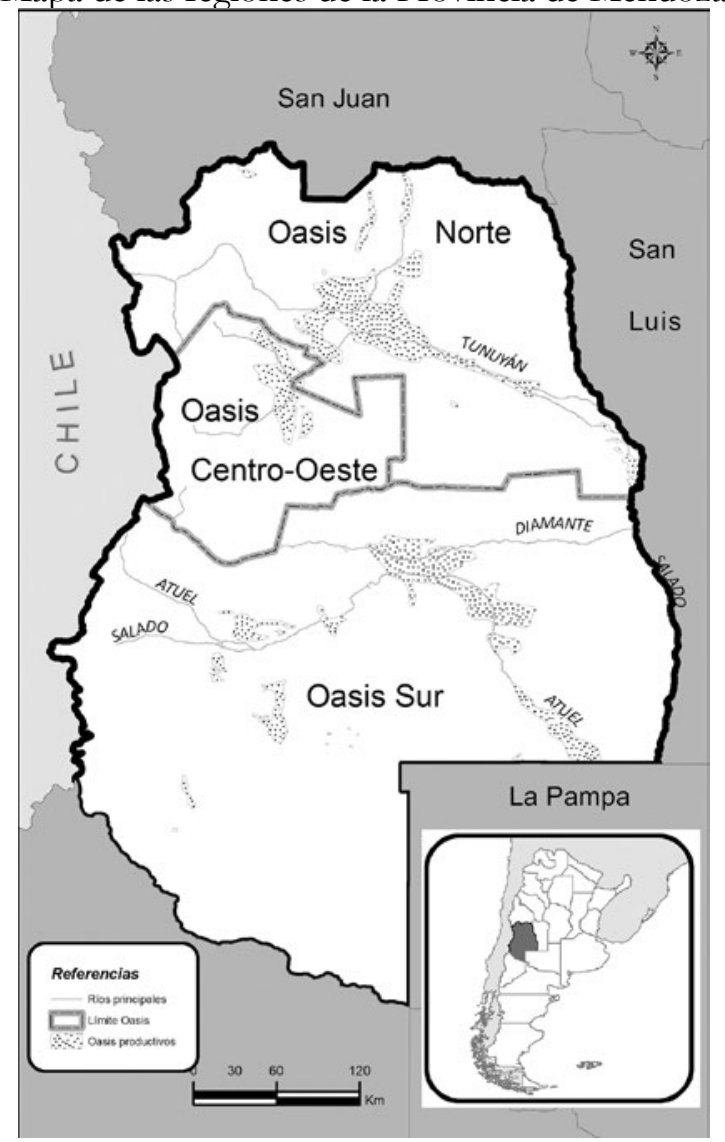

Fuente: Elaboración propia 
Esto dio lugar a que haya una mayor movilidad de las personas entre el espacio rural y urbano que en otras regiones del país donde las distancias eran más significativas. Esta movilidad de personas también fue favorecida por la producción vitivinícola que demandaba gran cantidad de mano de obra en períodos muy puntuales a lo largo del año ${ }^{2}$. Esto facilitó que los sectores de menores recursos tuvieran ingresos a lo largo del año realizando diversas tareas, en el marco de una alta estacionalidad laboral. En Mendoza esta producción se basó en la pequeña propiedad -producto de un acceso más fácil a la tierra con relación a otras regiones del país- y en el trabajo familiar, que incluyó el trabajo de los menores como se ha mostrado en otro artículo ${ }^{3}$. Según la historiografía clásica estos factores habrían dado lugar a la construcción de una sociedad de clase media, "igualando", de alguna manera, las condiciones materiales de su población. Partiendo de este supuesto nos planteamos aquí ver qué relación puede encontrarse entre diferentes grupos sociales y el acceso a la educación elemental. Si el postulado de igualdad se cumpliría deberíamos encontrar niveles de educación similares entre el campo y la ciudad y entre los diferentes grupos sociales, aspecto que como veremos no sucedió.

Aquí partimos de la idea que el proceso de poblamiento y el acceso a la educación fue heterogéneo y que los alcances de bienestar no fueron equitativos. El Oasis Norte -que comprende la ciudad de Mendoza y los departamentos circundantes, definido aquí como Gran Mendoza) - vivió una transformación temprana de su fisonomía y de su estructura social desde mediados del siglo XIX. La expansión del comercio y del sector de servicios convirtió a esta región en el centro de atracción y desarrollo urbano más importante de la provincia. A partir de la segunda mitad del siglo XIX, y en el marco de la construcción del Estado Nacional, se consolidó el modelo vitivinícola como parte de un proyecto político-económico de la élite local. Dicha actividad, que tiene sus orígenes en la época virreinal, fue modernizada y orientada para satisfacer la demanda de un mercado

2 Juan Manuel Cerdá, "Mercado de trabajo y condiciones de vida en Mendoza a comienzos del siglo XX”, Mundo Agrario. Revista de Estudios Rurales, Vol. 6, No 12 (2006).

3 Juan Manuel Cerdá, "El trabajo infantil en la agricultura mendocina. Un ejercicio comparativo", en Trabajo agrícola. Una problemática vigente en la Argentina, ed. Juan Manuel Cerdá y Talía Violeta Gutiérrez (Buenos Aires: Editorial CICCUS, 2009), 159-180. 
interno creciente producto de la entrada de inmigrantes llegados del Mediterráneo ${ }^{4}$. Por su parte, a partir de la expansión de la frontera hacia el sur en la década de 1880 -luego del exterminio de los pueblos originarios-, se incorporaron nuevas tierras al modelo productivo vitivinícola y a partir de allí el crecimiento de la población en el Oasis Sur fue vertiginoso. Hasta el presente la provincia de Mendoza está fuertemente identificada con dicha actividad a pesar de que hoy no es la actividad principal ${ }^{5}$.

Esto permitió que la región de $\mathrm{Cuyo}^{6}$ en general y la provincia de Mendoza en particular se especializaran en esta agroindustria y se integraran al modelo agroexportador liderado por la región pampeana ${ }^{7}$. Un factor fundamental que facilitó todo este proceso fue el ferrocarril. La llegada de éste a la provincia (1885), al mismo tiempo que limitó la expansión de Mendoza como productora de cereales y carnes - producto de las ventajas comparativas que tenía la "pampa húmeda"- permitió organizar la economía provincial en torno a la producción vitivinícola, aprovechando sus propias ventajas comparativas derivadas del clima y el tipo de suelo. El ferrocarril posibilitó una mejor y más rápida comunicación con el litoral Atlántico y especialmente con los mercados de consumo más importantes del país, como eran Buenos Aires y Rosario.

Esto permite pensar en una cuasi unificación del espacio rural a las ciudades y su consecuente menor urbanización en términos relativos a nivel nacional. Como lo muestran los censos, la población que vivía en el sector rural representaba el 48 \% del total de Argentina en 1914, mientras que en Men-

4 Pablo Lacoste, El vino del inmigrante: los inmigrantes europeos y la industria vitivinícola argentina: su incidencia en la incorporación, difusión y estandarización del uso de topónimos europeos 18521980 (Mendoza: Consejo Empresario Mendocino, 2003).

5 En relación al PBI hoy la vitivinicultura en la provincia fue superada por la minería y los hidrocarburos, sin embargo, la identificación con dicha actividad está muy marcada.

6 Hay diferentes definiciones de esta región, pero tomaremos aquí la que incluye en ella a las provincias de San Juan, San Luis y Mendoza.

$7 \quad$ Entre otros ver Wiliams Fleming, Regional development and transportation in Argentina. Mendoza and the Gran Oeste Argentino Railroad, 1885-1914 (New York \& London: Garland Publishing, 1987); Rodolfo Richard-Jorba, Poder, economía y espacio en Mendoza. 1850-1900. Del comercio ganadero a la agroindustria vitivinícola (Mendoza: Editorial de la Universidad Nacional de Cuyo. Facultad de Filosofía y Letras, 1998) y Patricia Collado, "Mendoza, periferia de la periferia próspera. Un análisis sobre el modelo de desarrollo regional" (Revista confluencia, año 1, N 1, (invierno 2003). 
doza representaba el $68 \%$. Para 1947 la diferencia se había reducido pero la provincia se mantenía por arriba de la media nacional: 38\% del total de la población del país vivía en áreas rurales, mientras que en Mendoza llegaba al $50 \%$. Por otro lado, esto implicó una mayor integración entre las actividades del ámbito rural con las urbanas que se vio reflejado en un mercado de trabajo marcado por la pluriactividad desde períodos muy tempranos ${ }^{8}$.

A partir de este marco general, se analizaron cuáles fueron los niveles de analfabetismo 9 y los motivos de deserción escolar en la población de Mendoza a partir de fuentes tanto cuantitativas como cualitativas de la época, con el fin de mostrar las diferencias interregionales y las causas que las provocaban en el caso particular de la provincia. Para ello se ha realizado la reconstrucción de los niveles de analfabetismo a nivel provincial y regional, así como también de las series de asistencia promedio de alumnos, del total de maestros y de las escuelas existentes para gran parte del período en estudio. Este análisis permitió, por un lado, evaluar la existencia de oferta educativa y su evolución y, por otro lado, los indicadores de resultados educativos, es decir, los niveles de analfabetismo y deserción escolar.

\section{REVISIÓN BIBLIOGRÁFICA}

En general, la bibliografía sobre educación en Argentina se ha caracterizado por estudiar las instituciones, los conflictos en torno a la educación y su relación con la política, el Estado y la economía, cruzados cada uno de ellos por encuadres teórico-metodológicos diversos ${ }^{10}$. En este sentido, se destacan los diversos trabajos de Juan Carlos Tedesco y Adriana Puiggrós,

8 Juan Manuel Cerdá, "Mercado de trabajo".

9 Según los censos, analfabeto es toda persona que no sabe leer y escribir, mientras que semianalfabeto es aquella persona que sabe leer pero no escribir. Veremos más adelante que en los diferentes censos fue cambiando la edad a partir de la cual se determina dicho valor, aspecto que dificulta su comparabilidad en el tiempo.

10 Algunos balances que ayudaron a la contextualización del problema y de su desarrollo historiográfico son Adrián Ascolani, "Historia de la historiografía educacional argentina. autores y problemas (1910-1990)", en La educación en Argentina. Estudios de Historia, ed. Adrián Ascolani (Rosario: Ediciones del Arca, 1999), Adrián Ascolani, "La investigación reciente en Historia de la educación argentina. Campo de estudio, interdisciplinar y problemáticas actuales", en El sistema educativo en Argentina,comp. Adrián Ascolani (Rosario: Estudios de historia, Libro Editor, 2010). 
quienes han desarrollado numerosos estudios sobre cada uno de estos aspectos $^{11}$. Juan Carlos Tedesco se centró en el estudio de las relaciones de poder y cómo el Estado ejerció el control-dominación sobre los diferentes sectores de la sociedad a partir de la educación. Para este autor la educación fue parte del proyecto del Estado Oligárquico en el que ocupaba un lugar central, con el fin de establecer un control social y un orden hegemónico. En cierta medida, Tedesco fue pionero en proponer esta visión donde la educación se sustentaba en causas políticas, diferenciándose así de los análisis más tradicionales institucionalistas o biográficos de figuras célebres de la educación argentina. En alguna medida, esta línea fue continuada y ampliada por los trabajos sobre educación de Mariano Plotkin y María Inés BarberoyDarío Roldán ${ }^{12}$. Estos trabajos han sostenido que la educación estaba orientada a la incorporación a la vida política tanto de los extranjeros como de los nativos resaltando la acción política del Estado en la construcción de la ciudadanía a finales del siglo XIX y comienzos del XX. Desde esta mirada la educación en la Argentina del novecientos sirvió como una forma de naturalización de las reglas de la vida política democrática contribuyendo a aumentar la participación de todos los sectores de la sociedad a un proceso necesario de integración social ${ }^{13}$. Por el contrario, Adriana Puiggrós sostuvo que el verdadero propósito de los grupos dominantes era la homogeneización de los individuos (nativos y extranjeros) y su inclusión en un proyecto político nacional ${ }^{14}$. La búsqueda de un análisis interdisciplinario y la integración de la bibliografía sobre temas educativos llevaron a Puiggrós a desarrollar y compilar el proyecto "La educación en las provincias y territorios nacionales 1885-1945", donde se da cuenta de

11 Entre los textos más relevantes sobre la evolución de la educación en Argentina se encuentran: Juan Carlos Tedesco, Educación y sociedad en la Argentina (1880-1945) (Buenos Aires: Nueva edición ampliada y 1ra. en Biblioteca Dimensión Argentina, Ediciones Solar, 1986), y Adriana Puiggrós, La educación en las provincias y territorios nacionales 1885-1945, (Buenos Aires: Colección Historia de la Educación en la Argentina, Editorial Galerna, 1993).

12 Mariano Plotkin, "Política, educación y nacionalismo en el Centenario", en Todo es Historia No 221 (1985) y María Inés Barbero y Darío Roldán, "Inmigración y educación (1880-1910). La escuela como agente de integración”, Cuadernos de historia regional, Vol. III, No 9 (1987).

13 María Inés Barbero y Darío Roldán, "Inmigración y educación..., 80.

14 Adriana Puiggrós, Sujetos, disciplina y curriculum, en los orígenes del sistema educativo argentino (Buenos Aires: Editorial Galerna, 1990). 
dicho proceso en los diferentes espacios provinciales muy disímiles ${ }^{15}$. Un interesante cruce entre ambas posturas es el que realiza Lilia Ana Bertoni en su libro Patriotas, cosmopolitas y nacionalistas. A partir de un análisis que se centra en fuentes documentales para la Ciudad de Buenos Aires la autora da cuenta de un proceso complejo donde se cruza la construcción de la nacionalidad, la necesidad de incrementar la educación de los niños y las limitaciones que tenía el Estado Nacional de concretar la universalización de la educación básica. ${ }^{16}$ La educación aparece como un escenario de conflicto no solo político de intereses que cruzan la nacionalidad, la formación de individuos para el mercado y la construcción del Estado. A pesar de los diferentes abordajes estos referentes se han concentrado en las últimas décadas del siglo XIX y comienzos del XX donde el problema de la universalización de la educación fue en todo el país. Sin embargo, las implicancias de las políticas, los contextos económicos locales y las políticas públicas fueron muy diversas.

Pero quizás los estudios que más han aportado para pensar este problema en la provincia de Mendoza hayan venido de la mano de la sociología de la educación. En especial del trabajo realizado por Daniel Filmus, Ana Miranda y Julio Zelarayán, quienes han podido mostrar la relación entre el déficit educacional de los menores y su participación en el mercado de trabajo ${ }^{17}$. Según estos autores, en la década de 1990 las condiciones socioeconómicas de las familias fueron determinantes para medir las trayectorias educativas de los jóvenes. En particular, han verificado que aquellos jóvenes provenientes de hogares de bajos recursos se enfrentan con la necesidad de aportar a los ingresos familiares insertándose, por ello, más tempranamente en el mercado de trabajo que aquellos que provienen de

15 Adriana Puiggrós, La educación en las provincias..., Este compendio realmente interesante debe ser recuperado para los estudios sociales. Si bien los trabajos no mantienen una coherencia analítica ni teórica, hecho que fuera reconocido por la propia compiladora en la introducción del libro, han servido como base fundamental para las comparaciones realizadas en este artículo.

16 Lilia Ana Bertoni, Patriotas, cosmopolitas y nacionalistas. La construcción de la nación argentina a fines del siglo XIX (Buenos Aires: Fondo de Cultura Económica, 2001).

17 Daniel Filmus, Ana Miranda y Julio Zelarayán, "En el mercado de trabajo, ¿el saber no ocupa lugar?: egresados de la escuela media y primer año de inserción laboral", 5to. Congreso Nacional de Estudios del Trabajo (Buenos Aires: ASET, 2001). 
familias de sectores medios y medio-altos los que permanecen por más tiempo en el sistema educativo. Asimismo, pudieron observar una clara correlación entre el nivel de escolarización de la madre y la probabilidad de los jóvenes de continuar con sus estudios. Según los autores, ello sugiere la presencia de un importante proceso de transmisión intergeneracional de desventajas ${ }^{18}$. En esta perspectiva subyace la idea de que la educación es una variable que nos aproxima a la problemática de la desigualdad y la reproducción de situaciones de inequidad social así como las diferencias entre los grupos sociales.

En la revisión de la literatura no se han encontrado trabajos que contengan una perspectiva histórica a partir de la cual se analice la educación como una variable asociada al progreso social y, en especial, que focalice sobre el impacto que esta tuvo en el desarrollo de los menores durante la primera mitad del siglo XX. Sin lugar a dudas, algunos de los factores que han influido en este vacío historiográfico han sido las limitaciones de las fuentes y la imposibilidad de reconstruir datos completos para dicho período; tarea que intentamos salvar aquí con las fuentes cualitativas que se han encontrado para la provincia de Mendoza.

\section{Dinámica y distribución espaCial del analfabetismo en MENdoza}

A partir de los datos compilados en los censos nacionales, podemos advertir que en materia educativa Mendoza se ubicó próxima al promedio nacional desde 1869 a 1947. La provincia tenía 83,3 \% de analfabetos en el total de su población en 1869, valores que se redujeron rápidamente a $58 \%$ para 1895 y $42 \%$ en 1909 . Este nivel se mantuvo relativamente estable entre 1909 y 1914 y volvió a descender hasta mediados del siglo XX, cuando el analfabetismo alcanzó 17,3 \%, según el Cuarto Censo Nacional de $1947^{19}$. (Gráfico 1)

18 Otro trabajo que llega a resultados similares fue realizado por Silvio Feldman, "El trabajo de los adolescentes en Argentina. ¿Construyendo futuro o consolidando la postergación social?” en Adolescencia, pobreza, educación y trabajo, eds. Irene Konterllnik y Cintia Jacinto (Buenos Aires: Losada, 1996).

19 Datos obtenidos de los Censos Nacionales de Población correspondientes a los años 1895, 1914 y 1947 y del Censo Provincial de Población de 1909. 


\section{Gráfico 1}

Porcentaje de la población analfabeta según los censos nacionales por provincia

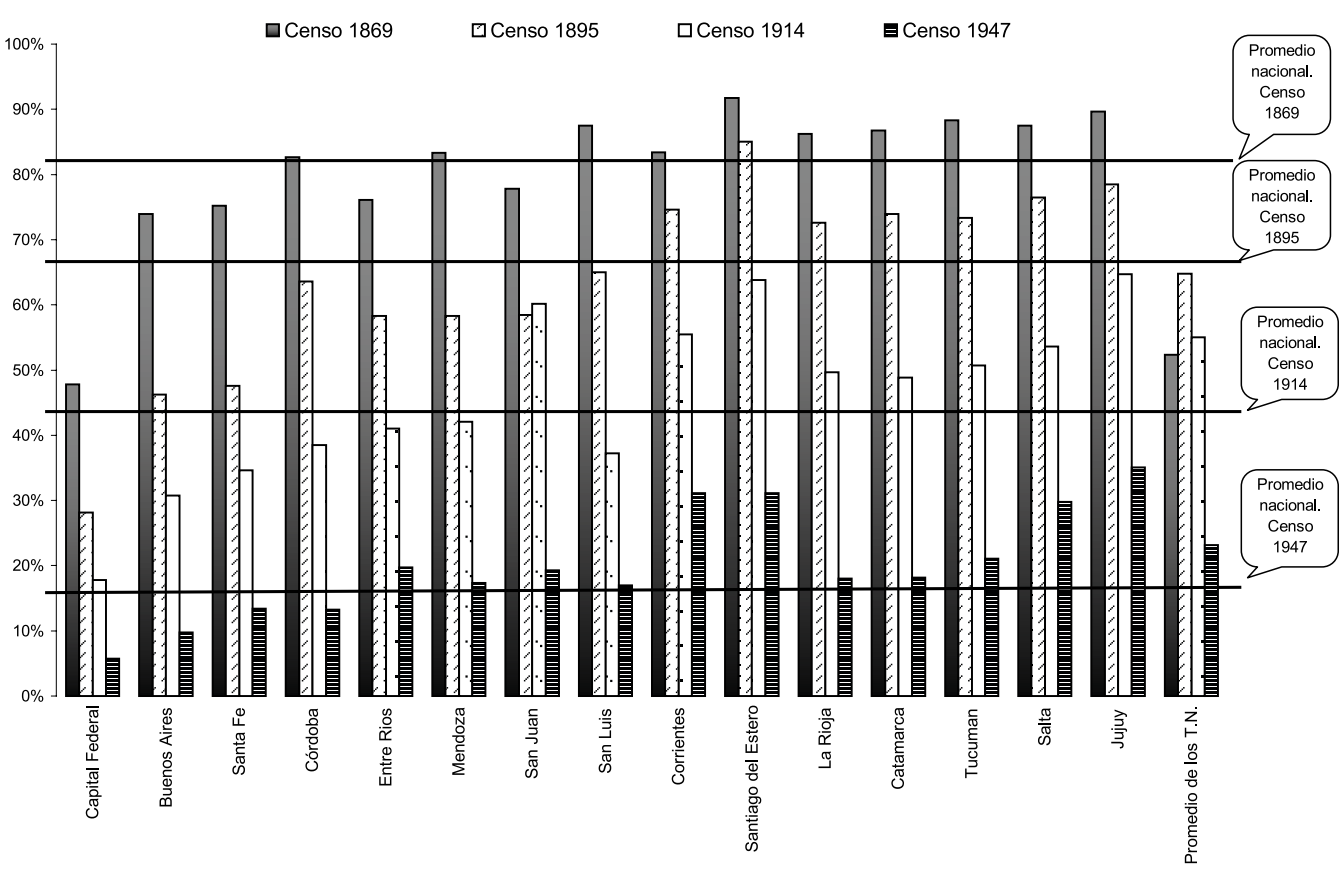

Fuente: Elaboración propia sobre la base de los Censos Nacionales de Población

Nota aclaratoria: Mientras que las estimaciones de la cantidad de analfabetos en los censos de 1895 y 1909 se realizaron sobre la base de los individuos mayores a 6 años, el censo de 1947 tomó la edad de 14 años como edad mínima para medir el analfabetismo, entendiendo que esta era la edad a partir de la cual el individuo terminaba su instrucción básica. Como puede apreciarse, el cambio metodológico es significativo lo que provocó una subcaptación de los analfabetos debido al sesgo de selección. De todas maneras, podemos presuponer que este sesgo fue relativamente homogéneo en todas las provincias

Si se ordena de forma creciente este indicador se puede advertir que las provincias de la región pampeana ${ }^{20}$ se ubicaron sistemáticamente en la cola inferior de la distribución - con menor porcentaje de analfabetos-, luego las provincias de la región de Cuyo, seguidas por las provincias del norte y finalmente se ubican los territorios nacionales. Esto estaría mos-

20 La región pampeana incluye a las provincias de Buenos Aires, Santa Fe, Córdoba y Entre Ríos. 
trando una suerte de relación positiva (y esperable) entre educación y nivel de desarrollo donde, por un lado, están las provincias "ricas" con niveles bajos de analfabetismo y, por otro, provincias "pobres" con niveles altos de analfabetismo ${ }^{21}$. Sin embargo, estos promedios esconden diferencias significativas al interior de cada provincia.

Cuadro 1. Porcentaje de población analfabeta en Mendoza por departamento

\begin{tabular}{lccc}
\hline Departamentos & $\mathbf{1 8 9 5}$ & $\mathbf{1 9 0 9}$ & $\mathbf{1 9 4 7}$ \\
\hline Ciudad de Mendoza & $42,1 \%$ & $28,6 \%$ & $7,6 \%$ \\
Godoy Cruz & $51,3 \%$ & $38,8 \%$ & $10,8 \%$ \\
Guaymallén & $50,8 \%$ & $38,6 \%$ & $14,6 \%$ \\
Luján de Cuyo & $58,2 \%$ & $44,8 \%$ & $19,4 \%$ \\
Maipú & $62,0 \%$ & $46,0 \%$ & $19,1 \%$ \\
Gran Mendoza & $\mathbf{5 2 , 9} \%$ & $\mathbf{3 9 , 3} \%$ & $\mathbf{1 4 , 3} \%$ \\
Gran Mendoza excluyendo & & & \\
a la ciudad de Mendoza & $\mathbf{5 5 , 6} \%$ & $\mathbf{4 2 , 0} \%$ & $\mathbf{1 6 , 0} \%$ \\
Junín & & & \\
La Paz & $64,2 \%$ & $44,0 \%$ & $20,8 \%$ \\
Rivadavia & $65,2 \%$ & $51,5 \%$ & $25,7 \%$ \\
San Martín & $59,0 \%$ & $46,0 \%$ & $21,1 \%$ \\
Santa Rosa & $63,9 \%$ & $47,6 \%$ & $20,3 \%$ \\
Zona Este & $68,0 \%$ & $38,4 \%$ & $22,9 \%$ \\
Lavalle & $\mathbf{6 4 , 1} \%$ & $\mathbf{4 5 , 5} \%$ & $\mathbf{2 2 , 0} \%$ \\
Las Heras & $81,9 \%$ & $63,9 \%$ & $33,8 \%$ \\
Zona Norte & $60,9 \%$ & $45,7 \%$ & $17,5 \%$ \\
San Rafael & $\mathbf{7 1 , 4} \%$ & $\mathbf{5 4 , 8} \%$ & $\mathbf{2 3 , 5} \%$ \\
Oasis Sur & $81,5 \%$ & $57,3 \%$ & $23,4 \%$ \\
San Carlos & $\mathbf{8 1 , 5} \%$ & $\mathbf{5 7 , 3} \%$ & $\mathbf{2 3 , 4} \%$ \\
Tunuyán & $70,8 \%$ & $53,6 \%$ & $25,0 \%$ \\
Tupungato & $\mathbf{7 9 , 3} \%$ & $61,6 \%$ & $23,6 \%$ \\
Valle de Uco & $64,3 \%$ & $49,7 \%$ & $26,2 \%$ \\
\hline Promedio provincial & $\mathbf{7 1 , 5 \%}$ & $\mathbf{5 5 , 0} \%$ & $\mathbf{2 4 , 9} \%$ \\
\hline
\end{tabular}

Fuente: Elaboración propia con base en los Censos Nacionales de Población y al Censo Provincial de población de 1909. No hay datos desagregados por departamento para los censos de 1869 y 1914.

En el dato de analfabetismo correspondiente a San Rafael se ha decidido sumar los valores de Gral. Alvear para el año 1947 para poder establecer la comparación con los censos anteriores

21 La región pampeana comprende a las provincias de Buenos Aires, Córdoba, Santa Fe y Entre Ríos; las provincias de Cuyo son: San Luis, Mendoza y San Juan; el noroeste está integrado por las provincias de Santiago del Estero, La Rioja, Catamarca, Tucumán, Jujuy y Salta. 
En el caso de Mendoza ${ }^{22}$ es posible observar que en cada uno de los años censales las discrepancias en el porcentaje de analfabetismo entre departamentos son muy marcadas (Cuadro 1). Estas diferencias se observan también a nivel de región. La única región que se ubicó por debajo de la media provincial a lo largo de todo el período fue el Gran Mendoza, destacándose dentro de ella los departamentos de la ciudad de Mendoza, Godoy Cruz y Guaymallén, estos últimos sobre todo en el último período intercensal. En particular, la ciudad de Mendoza es la que muestra los índices más bajos de analfabetismo a lo largo de todo el período. (Gráfico 2)

\section{Gráfico 2}

Evolución del analfabetismo en Mendoza por regiones

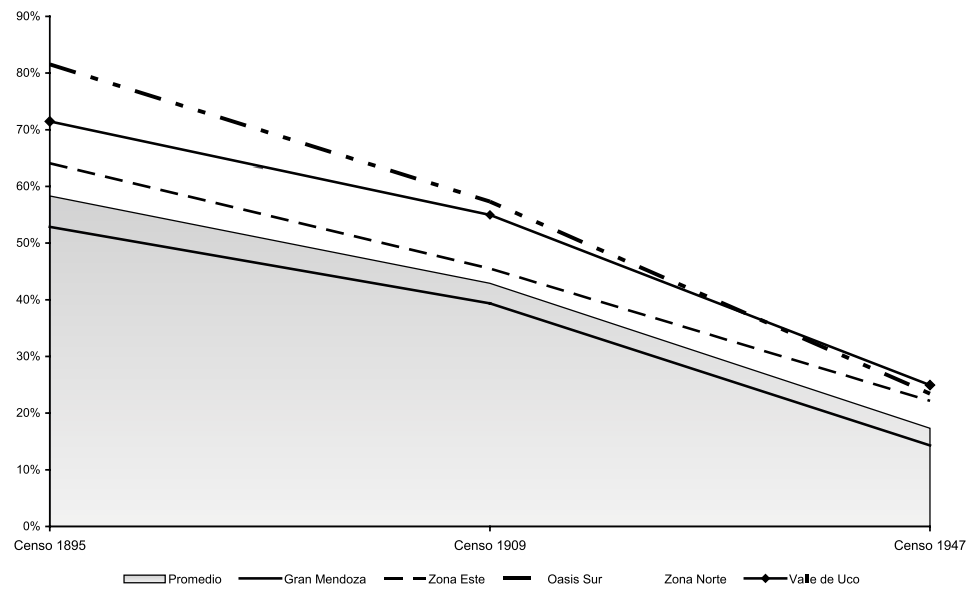

Fuente: Elaboración propia con base en los Censos Nacionales de Población correspondientes a 1895 y 1947 y al Censo Provincial de Población de 1909

A pesar de las dificultades que existen en las fuentes censales para comparar en el tiempo el analfabetismo en los menores ${ }^{23}$ se percibe una tendencia decreciente y constante que acompañó el ritmo observado en el promedio nacional ${ }^{24}$. El Gráfico 2 también permite observar que, producto de las

22 Para analizar este fenómeno se ha dividido a la provincia en cinco subregiones agrupando a los departamentos de la siguiente manera: Gran Mendoza: Mendoza Capital, Godoy Cruz, Guaymallén, Luján de Cuyo y Maipú; zona este: Junín, La Paz, Rivadavia, San Martín y Santa Rosa; zona norte: Lavalle y Las Heras; Oasis Sur: San Rafael; y Valle de Uco: San Carlos, Tunuyán y Tupungato.

23 Las diferencias metodológicas o la falta de datos a nivel desagregado entre los censos en algunos casos hace imposible construir una serie de largo plazo completamente homogénea.

24 Según el Censo Nacional de 1869 el 87,6 \% de los menores no asistían a la escuela, mientras que el Censo Provincial de 1909 identificó al 56,6\% de los niños entre 6 y 14 años como analfabetos y $61 \%$ de los que asistían a las escuelas. Para 1914, el porcentaje de niños en edad escolar analfabetos ascendía a 38,7 \% y $3,1 \%$ eran semianalfabetos. Si bien estos datos no son plenamente comparables (la asistencia no garantiza la alfabetización de los niños), permiten obtener una idea del aumento en el grado de 
diferencias en el ritmo de descenso en el nivel de analfabetismo, se redujo la brecha entre los promedios regionales hacia comienzos del siglo XX, situación que luego se mantuvo constante hasta el final del período. Esto estaría dado por la expansión del sistema educativo en todo el país durante la primera década del siglo XX que implicó que aquellos departamentos de la provincia más rezagados pudieran mejorar su posición relativa en materia educativa ${ }^{25}$.

Este decrecimiento del analfabetismo de los menores en la provincia estuvo asociado a un mayor acceso a la educación a partir de un aumento de la asistencia escolar $\left(\mathrm{R}^{2}=0,81\right)$ y un incremento en la cantidad de maestros $\left(R^{2}=0,95\right)$ en las primeras décadas del siglo XX. Sin embargo, esto se verificó en un contexto donde el número de establecimientos se mantuvo casi constante a lo largo de todo el período lo que implicó un aumento en el promedio de alumnos por escuela, pasando de 97 alumnos en 1905 a 116 alumnos en 1926. (Gráfico 3)

\section{Gráfico 3}

Evolución de escuelas, asistencia promedio de alumnos y total de maestros en la provincia, 1905-1926

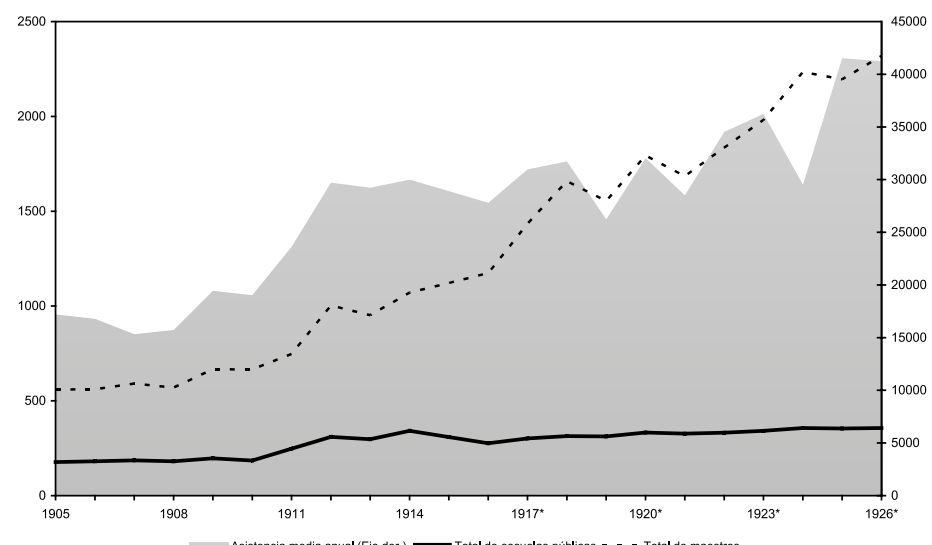

Fuente: Elaboración propia con base en el Censo Nacional de 1914, p.83, mientras que los datos de 1916 a 1926 son extraídos de: Leopoldo Suárez, El problema escolar en la provincia.

(Mendoza:s/d 1926), 16, 19, 23.

Nota: el dato de 1915 fue construido a partir de una estimación propia tomando como parámetro la tendencia central del período correspondiente a 1914 (Buenos Aires: s/d), 390-395. 
Entonces, esta dificultad debió ser compensada a través de un incremento de maestros, lo que permitió bajar la proporción de alumnos por docente. Si bien no es posible conocer la distribución de los docentes, el incremento debió ser un factor que influyó positivamente sobre el descenso del analfabetismo en la región y que debió incidir favorablemente en la calidad educativa $^{26}$. Según los datos brindados por Leopoldo Suárez, el mayor descenso se dio en el período 1911-1919, cuando la relación pasó de 47 a 21 alumnos por docente, relación que se mantuvo hasta el final del período para el cual tenemos datos ${ }^{27}$.

En este marco, el Gran Mendoza concentraba en su territorio más del 40 $\%$ de los establecimientos educativos de la provincia a lo largo de todo el período y, dentro de esta, la ciudad de Mendoza representaba el $15 \%$ del total de las escuelas de la provincia. Sin embargo, el mayor crecimiento en el número de escuelas se observó en el resto de las regiones y, en especial, en San Rafael donde la creación de nuevos edificios escolares fue constante (Gráfico 4). Estos datos permiten presumir que este fue el factor fundamental que explica el descenso del analfabetismo entre 1909 y 1914 en la región Sur de la provincia. En apenas cinco años (1909-1914) el departamento de San Rafael pasó de tener una de las poblaciones en edad escolar con los mayores índices de analfabetismo -en 1909 el analfabetismo rondaba el $80 \%$ - a ubicarse en 1914 cercano al $26 \%$, doce puntos porcentuales por debajo de la media provincial. ${ }^{28}$ Por el contrario, las regiones del norte y el Valle de Uco -regiones rurales- quedaron rezagadas de esta mejora en infraestructura. Este factor podría explicar el menor dinamismo en la reducción del analfabetismo en esta región, especialmente en relación al Oasis Sur.

26 Leopoldo Suárez, El problema escolar en la provincia (Mendoza: s/d, 1926), Leopoldo Suárez se desempeñó como Director General de la Dirección General de Escuelas de la provincia de Mendoza durante el gobierno de Alejandro Orfila (1926-1928).

27 Según los datos obtenidos del Censo Nacional de 1914, la relación de alumnos por maestro para el promedio nacional era de 35. Las provincias con índices más bajos eran: Santa Fe (25), San Luis (29), Capital Federal (31) y Buenos Aires (33). Por el contrario, los niveles más elevados los encontramos en las provincias de Tucumán (47), Santiago del Estero (45) y Mendoza (45). Elaboración propia con base en los datos del Tercer Censo Nacional de Población de 1914.

28 Datos obtenidos del Tercer Censo Nacional de Población correspondiente al año 1914, tomo IX, 133. La media provincial de los menores entre 6 y 14 analfabetos para el año 1914 era de 38,7 \%. 


\section{Gráfico 4}

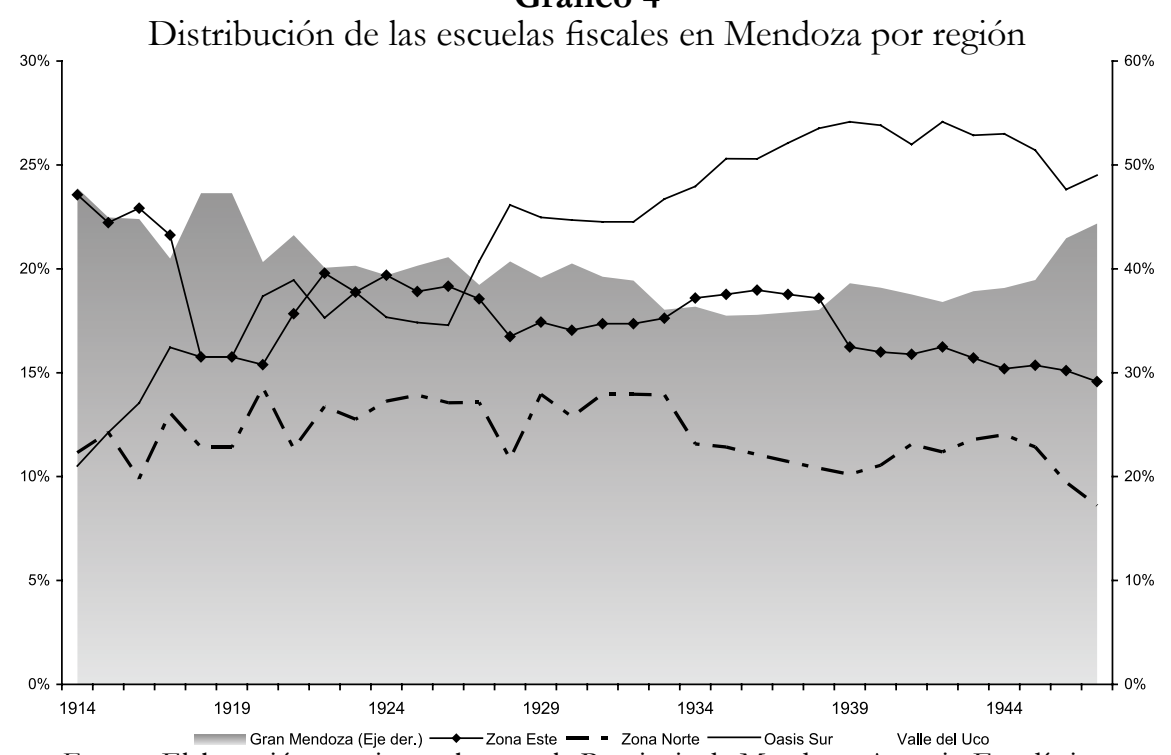

Fuente: Elaboración propia con base en la Provincia de Mendoza, Anuario Estadístico. Mendoza, Dirección General de Estadística de la Provincia de Mendoza. Varios años

A pesar de estas mejoras experimentadas durante el período bajo análisis persistió un porcentaje significativo de los menores que no completaban su instrucción básica en la provincia de Mendoza, y con fuertes diferencias entre las regiones. Esto se debió a diversos factores, entre los cuales se pueden identificar aquellos asociados a los déficits en la oferta educativa -falta de escuelas, malas condiciones de los establecimientos, distancia de los poblados dispersos, entre otros-, y otros asociados a la situación socioeconómica de las familias -especialmente trabajo infantil y pobreza-. Todos ellos influyeron de manera negativa sobre las posibilidades de los niños para asistir o completar la escuela primaria.

\section{El anAlfabetismo y SUS CAUSAS EN LA PERSPECTIVA DE LOS EXPERTOS}

Los informes realizados por Leopoldo Suárez (1926) y Dardo Olguín (1939) permiten dimensionar, para un período donde no contamos con datos cuantitativos, el problema del analfabetismo en la provincia ${ }^{29}$. Am-

29 Leopoldo Suárez, El problema..., y Dardo Olguín, El analfabetismo y sus factores (Mendoza: Editorial Best Hnos., 1939), Leopoldo Suárez fue Superintendente General de Irrigación, Ministro de 
bos funcionarios realizaron un balance exhaustivo del analfabetismo con un lapso de más de diez años entre uno y otro. En los informes se resaltan la gravedad del problema en la provincia y su importancia para los respectivos gobiernos. Los informes permiten echar alguna luz sobre los procesos ocurridos y analizar cuáles eran los problemas más acuciantes para los funcionarios con relación a la educación en Mendoza. Estos informes deben ser leídos no solo como un análisis de las condiciones políticas, sociales y económicas sino también como proyectos de políticas públicas que tenían entre sus objetivos disminuir el analfabetismo provincial. Por otra parte, estos coinciden con el informe preliminar del Cuarto Censo Escolar de 1943, marcando la pervivencia de los problemas identificados por los expertos ${ }^{30}$.

Los informes de Suárez y Olguín coincidieron en afirmar que el analfabetismo tenía consecuencias sociales muy importantes y que su erradicación era uno de los objetivos del Estado Provincial y Nacional. Según estos, las causas del analfabetismo podrían agruparse en dos grandes categorías: cuestiones estructurales del sistema educativo y factores sociales. Los autores coinciden en la escasez de escuelas y el mal estado de las existentes, hecho que era más preocupante en la campaña que en las grandes ciudades de la provincia. También era una constante el retraso en el pago de los salarios, la falta de docentes con títulos habilitantes (Suárez) o especializados (Olguín) y, por último, la necesidad de adecuar la currícula a las necesidades "diferentes" de las comunidades, haciendo especial referencia a la introducción de los contenidos de "educación práctica" para los sectores de bajos recursos o de sectores rurales ${ }^{31}$.

Industrias y Obras Públicas e interventor de la Dirección General de Escuelas durante los tres gobiernos radicales de la década del 20 (José Nestor Lencinas (1918-1919); Carlos Washinton Lencinas (1922-1924) y Alejandro Orfila (1926-1928)). Para una semblanza Suárez en la política provincial ver Patricia Barrio y Florencia Rodríguez Vázquez, "Instituciones, saberes y expertos para un Estado provincial: Leopoldo Suárez, de agrónomo a funcionario itinerante del lencinismo, Mendoza, 1918-1930 Boletín del Instituto de Historia Argentina y Americana “Dr. Emilio Ravignani”, tercera serie, No. 44 (primer semestre 2016): Por su parte, Darío Olguín fue secretario de la Junta Central de Analfabetismo (dependiente de la Dirección General de Escuelas) durante la gobernación de Rodolfo Segura (1938-1941).

30 República Argentina, IV Censo Escolar de la Nación. Correspondiente a 1943 (Buenos Aires, 1947).

31 Ver Leopoldo Suárez, El problema escolar..., 1-19. y Dardo Olguín, El analfabetismo y..., 41-59, $108-123$ y $135-152$. 
Uno de los problemas más graves que tuvieron que afrontar los sucesivos gobiernos provinciales durante las décadas de 1910 y 1920 fue el retraso en el pago de los salarios docentes que llevó, por otro lado, a la huelga de docentes de $1919^{32}$. Según Suárez:

“...un conjunto de fenómenos diversos, de honda repercusión en el cuerpo social, con carácter de conicidad algunos, y cuya expresión más inquietante y que más lastima el sentimiento público, es aquel significado por el atraso enorme en el pago de los sueldos de maestro al servicio de esta provincia. [...] A simple vista parecería ser que todo el problema radica en la indicada anomalía, tenazmente persistente como signo de descomposición, y que apuntada con enérgico y seguro corte, permitiría volver al ritmo regular del organismo y a la plena robustez de la entidad afectada"33.

A pesar de esto, Suárez sostenía que si se tomara solo este aspecto estaríamos confundiendo "una manifestación superficial, a flor de piel, de la enfermedad, con la enfermedad misma" ${ }^{34}$. Para Suárez, tan grave como ello era "el pauperismo de la escuela misma, en la campaña, su decadencia, su misérrima condición de templo en ruinas y sin dioses...", haciendo clara referencia no solo a las malas condiciones edilicias sino a la recurrente denuncia de falta de maestros con títulos de Maestros Normales Naciona$\operatorname{les}^{35}$. Por otro lado, otra preocupación de este funcionario era la ausencia y deserción de los alumnos, ya que finalmente era el factor fundamental que explicaba los niveles de analfabetismo en la provincia. Causa que sería compartida diez años más tarde por Dardo Olguín.

Para ambos, la deserción escolar también estaba asociada a las condiciones socioeconómicas de la población y, en especial, afectaba más a los pobladores de las zonas rurales que a los que vivían en las ciudades. En parti-

32 Jacinto Berardo De la Vega, Mendoza 1919: ¡Huelga! El nacimiento de la sindicalización del Magisterio mendocino (Mendoza: Ediciones Culturales de Mendoza, 1997).

33 Leopoldo Suárez, El problema escolar..., 10-11.

34 Leopoldo Suárez, El problema escolar..., 26.

35 Leopoldo Suárez, El problema escolar..., 26. 
cular, coincidieron en establecer que las principales causas del ausentismo o la deserción escolar de los menores estaban dadas por la necesidad de trabajar para incrementar los ingresos de las familias:

"El trabajo de los niños alcanza vastas proporciones. Las cifras son elevadas en las ciudades, donde las fábricas, el comercio y los pequeños oficios callejeros los absorben. En la campaña, el porcentaje se supera, y no es exagerado afirmar que trabajan en las faenas rurales, muchas veces, a la par de los hombres. ${ }^{36}[\ldots]$ No bien los niños adquieren fuerza suficiente, los padres se aprovechan de su trabajo para acrecentar las entradas que, debido a sus escasos salarios, resultan insuficientes para el sostenimiento de una familia numerosa"37.

Por su parte, Suárez afirmaba en esta misma línea:

"En el caso especialísimo nuestro [Mendoza], concurren a perjudicar la inscripción y la asistencia escolar, las apremiantes exigencias de nuestra principal y casi única industria, la vitivinicultura, encontrándose con frecuencia, durante varias épocas del año, en pugna los intereses materiales de esta con los intereses morales de la escuela primaria. En los meses de marzo y abril por ejemplo, se realizan los trabajos de la vendimia o sea la recolección de la uva, tarea en la que ocupan de preferencia las mujeres y los niños, viene luego en julio y agosto, la junta o recolección de sarmientos y en octubre el desbrote de los viñedos" 38 .

36 Olguín, Dardo, El analfabetismo y..., 72.

37 Olguín, Dardo, El analfabetismo y..., 80.

38 Suárez, Leopoldo, El problema..., 20. Debe destacarse que Olguín escribió diez años más tarde un párrafo que es idéntico en contenido y, en cierta medida, en su redacción. Este dice "Mendoza es, por las características de su principal fuente de riqueza -la vitivinicultura-campo ampliamente propicio para explotar el trabajo de las criaturas, que como hemos visto, cuando son menores de 12 años les está terminantemente prohibido el trabajo, aún en tareas rurales (...) Terminada la vendimia, le sigue luego la poda y recolección de sarmiento, tarea que se realiza en los meses de julio y agosto. Posteriormente, cuando la vid empieza de nuevo a brotar, hay que desbrotarla y despampanarla. Esto ocurre en octubre. (Justamente cuando las escuelas se preparan para terminar el año escolar. En realidad el trabajo de la viña es continuo durante todo el año y los padres siempre encuentran motivos para obligar a trabajar a las criaturas". Dardo Olguín, El analfabetismo y..., 81. 
No solo se menciona como problemática la época de la vendimia, cuando los niños "trabajan a la par de los hombres" 39 , sino que también se hace referencia a un trabajo intermitente pero continuo a lo largo del año que competía con la asistencia escolar de los menores. Estas salidas del ámbito educativo condicionaban sus posibilidades de los menores de acceder a los conocimientos básicos (lectura, escritura y aritmética) y a un desarrollo intelectual posterior. En este sentido, Suárez afirma que:

"La generalidad de los niños que truncan su instrucción escriben con gran torpeza, no saben aún expresarse sin el auxilio de otros los conocimiento que escribieron en el aula, y si en el hogar no se complementa la enseñanza o si la índole del trabajo a que se consagran, no favorece su desarrollo cultural, retornan al poco tiempo a su condición de analfabetos, malogrando así ellos, la acción de la escuela.

Esta comprobación se obtiene al examinar los jóvenes de veinte años que hacen su conscripción miliar. La mayoría de los conscriptos han ido a la escuela pero sin sacar ningún provecho de ella" ${ }^{40}$.

Como se desprende de lo expuesto, la asistencia a la escuela no era una elección libre de los individuos o de sus familias sino que estaba fuertemente condicionada por el medio social, especialmente, por los factores económicos y productivos en los cuales se desarrollaban los menores. Suárez resalta la inacción de los funcionarios públicos que no hacían cumplir las leyes existentes en la provincia que prohibían el trabajo infantil desde $1918^{41}$.

39 Dardo Olguín, El analfabetismo..., 72.

40 Leopoldo Suárez, El problema..., 40.

41 Leopoldo Suárez, El problema..., 20. La ley provincial No 731 de 1918 prohibía el trabajo de los menores de 14 años si no habían completado su instrucción obligatoria $\left(\right.$ Art. $10^{\circ}$ ). Esta ley se vio reforzada por la sanción de la Ley Nacional de 1924 No 11.317 que prohíbe el trabajo en todo el territorio nacional de menores de 12 años o que comprendidos en la edad escolar (14 años) no hayan completado la instrucción básica. Esta ley hace explícita la prohibición del trabajo de menores aún en el trabajo rural $\left(\operatorname{art.} 1^{\circ}\right.$ ). Sin embargo, el problema del trabajo infantil es un problema recurrente en la provincia hasta el presente. Un trabajo que muestra esta continuidad histórica para la provincia es el de Juan Manuel Cerdá, "El trabajo infantil . 
Las aseveraciones de Suárez pueden sonar exageradas pero, diez años más tarde, Olguín hizo referencia a la misma situación, lo que marca una clara persistencia de esta situación a lo largo de la historia de la provincia. Basándose en los registros militares, Olguín afirmaba que el índice de analfabetismo entre los jóvenes de la provincia que eran incorporados al servicio militar alcanzaba el 19,2\%, aun cuando algunos de ellos habían concurrido alguna vez al colegio ${ }^{42}$. Esto era producto del desgranamiento educativo que sufrían las escuelas y que involucraba a todas las regiones de la provincia. Los datos suministrados por el autor muestran que tan solo el $21 \%$ de los niños de la provincia de Mendoza que comenzaban el colegio llegaba a cuarto grado. En este sentido, el Cuarto Censo de Educación nos brinda un marco más complejo al interior de la provincia. (Cuadro 2)

Cuadro 2. Población de 14 a 21 años que concurrió a la escuela, según haya o no terminado el nivel primario. Año 1943.

\begin{tabular}{|l|c|c|c|c|c|c|c|}
\hline \multirow{2}{*}{\begin{tabular}{l}
\multirow{2}{*}{ Departamento } \\
Total
\end{tabular}} & \multicolumn{2}{|c|}{ Terminó de cursar } & \multicolumn{2}{c|}{$\begin{array}{c}\text { Interrumpió } \\
\text { los estudios }\end{array}$} & \multicolumn{2}{c|}{$\begin{array}{c}\text { Finalizó } \\
\text { el nivel } \\
\text { primario \% }\end{array}$} \\
\cline { 3 - 8 } & & $\begin{array}{c}\text { Valores } \\
\text { absolutos }\end{array}$ & Porcentaje & $\begin{array}{c}\text { Valores } \\
\text { absolutos }\end{array}$ & Porcentaje & Varones & Mujeres \\
\hline Ciudad de Mendoza & 9.941 & 5.714 & $57,5 \%$ & 4.227 & $42,5 \%$ & $62,5 \%$ & $53,3 \%$ \\
\hline Godoy Cruz & 4.938 & 1.995 & $40,4 \%$ & 2.943 & $59,6 \%$ & $46,2 \%$ & $35,0 \%$ \\
\hline Guaymallén & 6.722 & 1.965 & $29,2 \%$ & 4.757 & $70,8 \%$ & $32,6 \%$ & $26,2 \%$ \\
\hline Luján & 3.442 & 642 & $18,7 \%$ & 2.800 & $81,3 \%$ & $21,6 \%$ & $15,9 \%$ \\
\hline Maipú & 5.479 & 946 & $17,3 \%$ & 4.533 & $82,7 \%$ & $20,3 \%$ & $14,3 \%$ \\
\hline $\begin{array}{l}\text { Gran Mendoza } \\
\text { (excluyendo } \\
\text { a la capital) }\end{array}$ & 20.581 & 5.548 & $27,0 \%$ & 15.033 & $73,0 \%$ & $30,7 \%$ & $23,5 \%$ \\
\hline Junín & 2.212 & 300 & $13,6 \%$ & 1.912 & $86,4 \%$ & $13,9 \%$ & $13,2 \%$ \\
\hline La Paz & 529 & 83 & $15,7 \%$ & 446 & $84,3 \%$ & $19,2 \%$ & $12,7 \%$ \\
\hline Rivadavia & 3.055 & 472 & $15,5 \%$ & 2.583 & $84,5 \%$ & $16,6 \%$ & $14,3 \%$ \\
\hline San Martín & 3.815 & 689 & $18,1 \%$ & 3.126 & $81,9 \%$ & $19,8 \%$ & $16,5 \%$ \\
\hline Santa Rosa & 742 & 71 & $9,6 \%$ & 671 & $90,4 \%$ & $11,0 \%$ & $8,2 \%$ \\
\hline Zona Este & 10.353 & 1.615 & $15,6 \%$ & 8.738 & $84,4 \%$ & $16,9 \%$ & $14,4 \%$ \\
\hline Las Heras & 2.527 & 516 & $20,4 \%$ & 2.011 & $79,6 \%$ & $23,5 \%$ & $17,5 \%$ \\
\hline Lavalle & 1.112 & 91 & $8,2 \%$ & 1.021 & $91,8 \%$ & $7,8 \%$ & $8,6 \%$ \\
\hline Zona Norte & 3.639 & 607 & $16,7 \%$ & 3.032 & $83,3 \%$ & $18,7 \%$ & $14,8 \%$ \\
\hline
\end{tabular}

42 Sin ser el registro de enrolamiento un censo o una encuesta estratificada siempre se había acercado a los valores promedios de los censos nacionales, lo que hace presumir que, ante la ausencia de datos certeros, podía ser usada como fuente alternativa. Dardo Olguín, El analfabetismo..., 28-38. 


\begin{tabular}{|l|c|c|c|c|c|c|c|}
\hline San Rafael & 9.306 & 1.907 & $20,5 \%$ & 7.399 & $79,5 \%$ & $21,3 \%$ & $9,0 \%$ \\
\hline Gral. Alvear & 2.506 & 405 & $16,2 \%$ & 2.101 & $83,8 \%$ & $16,9 \%$ & $15,5 \%$ \\
\hline Oasis Sur & 11.812 & 2.312 & $19,6 \%$ & 9.500 & $80,4 \%$ & $20,4 \%$ & $18,8 \%$ \\
\hline San Carlos & 1.497 & 144 & $9,6 \%$ & 1.353 & $90,4 \%$ & $10,3 \%$ & $8,9 \%$ \\
\hline Tunuyán & 1.171 & 146 & $12,5 \%$ & 1.025 & $87,5 \%$ & $13,0 \%$ & $12,0 \%$ \\
\hline Tupungato & 602 & 73 & $12,1 \%$ & 529 & $87,9 \%$ & $13,6 \%$ & $10,6 \%$ \\
\hline Valle de Uco & 3.270 & 363 & $11,1 \%$ & 2.907 & $88,9 \%$ & $11,9 \%$ & $10,3 \%$ \\
\hline Total & 59.596 & 16.159 & $27,1 \%$ & 43.437 & $72,9 \%$ & $29,4 \%$ & $25,1 \%$ \\
\hline $\begin{array}{l}\text { *Total excluyendo a } \\
\text { la ciudad capital }\end{array}$ & 49.655 & 10.445 & $21,0 \%$ & 39.210 & $79,0 \%$ & $23,2 \%$ & $19,0 \%$ \\
\hline
\end{tabular}

Fuente: República Argentina, IV Censo Escolar de la Nación. Correspondiente a 1943, Buenos Aires, 1947, p. 426-427.

* En la última fila se incluyó el promedio provincial sin los valores de la ciudad capital. Se observa que los promedios disminuyen de manera significativa si se excluye a la ciudad ya que en ella los niveles de alfabetización, concurrencia y terminalidad educativa son más elevados que en el resto de la provincia

En primer lugar, se puede verificar que solo el 27,1 \% de los jóvenes relevados por el censo había terminado el ciclo básico obligatorio. Este cuadro muestra, asimismo, las diferencias intrarregionales, donde se repiten, por un lado, los contrastes entre la ciudad capital y el Gran Mendoza, departamento que duplica al promedio provincial. Por otro lado, las diferencias son sustanciales entre la capital y el resto de los departamentos aun dentro la misma región, característica que se mantiene de los censos anteriores.

Al mismo tiempo, resulta interesante evaluar las diferencias educativas por sexo a partir de la información que brinda este Censo. Como se observa en las dos últimas columnas del Cuadro 2, los hombres tuvieron más posibilidades de terminar sus estudios que las mujeres. En este sentido, se verifica en la provincia una situación similar a la nacional donde la mujer es penalizada en términos de acceso a la educación. Sin embargo, nuevamente, esta situación no es homogénea a lo largo del territorio provincial ya que aquellas viviendo en las ciudades tuvieron mayores posibilidades de finalizar sus estudios en relación a las mujeres rurales, duplicando la media provincial. De hecho, el lugar de residencia (urbano o rural) parecería tener una mayor incidencia que el género sobre el acceso a la educación en general y a la alfabetización en particular.

Por otro lado, el censo permite establecer el grado de desgranamiento de la población entre 14 y 21 años de edad que se educó o asistió alguna vez 
a la escuela (Cuadro 3). En este caso el censo muestra que las diferencias también eran significativas aquí entre la ciudad capital y el resto de las regiones. Mientras que el 57,5 \% de los jóvenes de la ciudad capital había terminado la primaria, el promedio provincial tan solo llegaba a 27,1\%. En este caso, la ciudad de Mendoza, junto a Godoy Cruz, se diferencia del resto de los departamentos que muestran indicadores más cercanos al promedio provincial. Asimismo, se verifican diferencias en el resto de las regiones, especialmente en el Oasis Sur que se ubica 4 puntos porcentuales por encima de las regiones Este y Norte de la provincia. Debe notarse que el promedio de esta última región esconde una diferencia significativa entre los departamentos que la componen.

Cuadro 3. Desgranamiento educativo de la población de 14 a 21 años, clasificada de acuerdo al último grado aprobado y según región

\begin{tabular}{|c|c|c|c|c|c|c|c|}
\hline & \multicolumn{7}{|c|}{ Ultimo grado aprobado } \\
\hline & 1 inf. & 1 sup. & 2do & 3ro & 4to & 5to & 6to \\
\hline Ciudad de Mendoza & $0,7 \%$ & $3,2 \%$ & $10,4 \%$ & $20,5 \%$ & $34,4 \%$ & $42,5 \%$ & $57,5 \%$ \\
\hline Godoy Cruz & $1,2 \%$ & $4,1 \%$ & $13,6 \%$ & $29,7 \%$ & $49,6 \%$ & $59,6 \%$ & $40,4 \%$ \\
\hline Guaymanllén & $1,9 \%$ & $6,5 \%$ & $20,5 \%$ & $41,0 \%$ & $62,9 \%$ & $70,8 \%$ & $29,2 \%$ \\
\hline Luján & $4,0 \%$ & $9,7 \%$ & $24,7 \%$ & $48,0 \%$ & $74,2 \%$ & $81,3 \%$ & $18,7 \%$ \\
\hline Maipú & $2,5 \%$ & $8,1 \%$ & $25,4 \%$ & $49,3 \%$ & $75,4 \%$ & $82,5 \%$ & $17,5 \%$ \\
\hline $\begin{array}{l}\text { Gran Mendoza } \\
\text { Gran Mendoza }\end{array}$ & $1,7 \%$ & $5,7 \%$ & $17,4 \%$ & $34,8 \%$ & $55,0 \%$ & $63,1 \%$ & $36,9 \%$ \\
\hline $\begin{array}{l}\text { excluyendo a la } \\
\text { ciudad capital }\end{array}$ & $2,2 \%$ & $6,9 \%$ & $20,8 \%$ & $41,7 \%$ & $64,9 \%$ & $73,0 \%$ & $27,0 \%$ \\
\hline Junín & $3,2 \%$ & $9,4 \%$ & $27,2 \%$ & $53,4 \%$ & $81,0 \%$ & $86,4 \%$ & $13,6 \%$ \\
\hline La Paz & $3,8 \%$ & $12,1 \%$ & $34,6 \%$ & $55,8 \%$ & $76,6 \%$ & $84,3 \%$ & $15,7 \%$ \\
\hline Rivadavia & $4,4 \%$ & $10,0 \%$ & $27,2 \%$ & $51,1 \%$ & $78,5 \%$ & $84,5 \%$ & $15,5 \%$ \\
\hline San Martín & $2,7 \%$ & $8,2 \%$ & $26,5 \%$ & $50,4 \%$ & $74,7 \%$ & $81,9 \%$ & $18,1 \%$ \\
\hline Santa Rosa & $1,6 \%$ & $10,2 \%$ & $30,2 \%$ & $58,8 \%$ & $83,0 \%$ & $90,4 \%$ & $9,6 \%$ \\
\hline Zona Este & $3,3 \%$ & $9,3 \%$ & $27,5 \%$ & $52,1 \%$ & $77,8 \%$ & $84,4 \%$ & $15,6 \%$ \\
\hline San Rafael & $3,3 \%$ & $10,0 \%$ & $28,9 \%$ & $50,5 \%$ & $73,6 \%$ & $79,5 \%$ & $20,5 \%$ \\
\hline Gral. Alvear & $2,3 \%$ & $10,1 \%$ & $34,0 \%$ & $58,8 \%$ & $77,8 \%$ & $83,8 \%$ & $16,2 \%$ \\
\hline Zona Sur & $3,1 \%$ & $10,0 \%$ & $30,0 \%$ & $52,3 \%$ & $74,5 \%$ & $80,4 \%$ & $19,6 \%$ \\
\hline Las Heras & $2,4 \%$ & $8,9 \%$ & $25,1 \%$ & $49,6 \%$ & $72,3 \%$ & $79,6 \%$ & $20,4 \%$ \\
\hline Lavalle & $5,2 \%$ & $13,6 \%$ & $45,0 \%$ & $72,8 \%$ & $88,1 \%$ & $91,8 \%$ & $8,2 \%$ \\
\hline Zona Norte & $3,3 \%$ & $10,4 \%$ & $31,2 \%$ & $56,7 \%$ & $77,2 \%$ & $83,3 \%$ & $16,7 \%$ \\
\hline San Carlos & $4,4 \%$ & $14,8 \%$ & $38,3 \%$ & $62,1 \%$ & $83,8 \%$ & $90,4 \%$ & $9,6 \%$ \\
\hline Tunuyán & $3,1 \%$ & $9,9 \%$ & $33,4 \%$ & $60,5 \%$ & $82,1 \%$ & $87,5 \%$ & $12,5 \%$ \\
\hline Tupungato & $2,7 \%$ & $12,5 \%$ & $36,2 \%$ & $59,5 \%$ & $80,4 \%$ & $87,9 \%$ & $12,1 \%$ \\
\hline Valle de Uco & $3,6 \%$ & $12,6 \%$ & $36,1 \%$ & $61,1 \%$ & $82,6 \%$ & $88,9 \%$ & $11,1 \%$ \\
\hline $\begin{array}{l}\text { romedio } \\
\text { rovincial }\end{array}$ & $2,5 \%$ & $7,8 \%$ & $23,5 \%$ & $44,0 \%$ & $65,7 \%$ & $72,9 \%$ & $27,1 \%$ \\
\hline
\end{tabular}

Fuente: República Argentina. IV Censo Escolar de la Nación. Correspondiente a 1943. Buenos Aires, 1947. pp. $428-429$

Si tomamos como referencia al tercer grado, tenemos que el $44 \%$ de los menores de la provincia abandonaron la escuela en dicho año, porcentaje 
que se elevaba al $52 \%$ en las regiones Este y Sur, en tono al $56 \%$ en las regiones del Norte y del $60 \%$ en el Valle del Uco. En contraposición, solo el $20 \%$ de los niños de la ciudad de Mendoza dejan de asistir al colegio en ese grado. Asociado a esto, el censo estableció cuáles eran las causas más habituales de deserción escolar. Como se muestra en el Cuadro 4, el 40,5 $\%$ de los niños encuestados reveló que su abandono estuvo asociado al trabajo y el $9 \%$ a la pobreza. O sea, la mitad de los menores no concurría a la escuela porque las condiciones económicas del hogar lo impedían. Por otro lado, los factores estructurales asociados a la oferta educativa revisten una importancia menor. En efecto, el 8,9 \% declara no asistir por falta de grados y solo el 8,3\% por encontrarse alejado de la escuela.

Cuadro 4. Causas de abandono escolar, según región y sexo.

Año 1943.

\begin{tabular}{|c|c|c|c|c|c|c|c|c|c|c|}
\hline Regiones & Trabajo & Enfermedad & Edad & $\begin{array}{c}\text { Falta de } \\
\text { grado }\end{array}$ & $\begin{array}{c}\text { Total } \\
\text { Distancia al } \\
\text { colegio }\end{array}$ & Pobreza & Negligencia & Repetición & Otros & Total \\
\hline Gran Mendoza & $40,5 \%$ & $8,3 \%$ & $0,7 \%$ & $3,1 \%$ & $5,0 \%$ & $12,7 \%$ & $9,2 \%$ & $1,9 \%$ & $18,7 \%$ & $100 \%$ \\
\hline Zona Este & $36,7 \%$ & $4,4 \%$ & $1,7 \%$ & $12,6 \%$ & $9,2 \%$ & $8,2 \%$ & $9,6 \%$ & $2,1 \%$ & $15,4 \%$ & $100 \%$ \\
\hline Zona Norte & $37,0 \%$ & $6,1 \%$ & $1,3 \%$ & $10,5 \%$ & $9,5 \%$ & $9,6 \%$ & $9,9 \%$ & $1,9 \%$ & $14,1 \%$ & $100 \%$ \\
\hline Oasis Sur & $40,9 \%$ & $2,9 \%$ & $3,1 \%$ & $13,4 \%$ & $11,0 \%$ & $6,0 \%$ & $6,3 \%$ & $1,8 \%$ & $14,6 \%$ & $100 \%$ \\
\hline Valle de Uco & $45,8 \%$ & $3,2 \%$ & $1,9 \%$ & $12,0 \%$ & $10,9 \%$ & $3,5 \%$ & $8,0 \%$ & $1,5 \%$ & $13,1 \%$ & $100 \%$ \\
\hline promedio & $40,5 \%$ & $5,5 \%$ & $1,6 \%$ & $8,9 \%$ & $8,3 \%$ & $9,0 \%$ & $8,5 \%$ & $1,9 \%$ & $15,8 \%$ & $100 \%$ \\
\hline \multicolumn{11}{|c|}{ Hombres } \\
\hline Gran Mendoza & $53,8 \%$ & $5,1 \%$ & $0,5 \%$ & $2,4 \%$ & $3,7 \%$ & $11,3 \%$ & $8,0 \%$ & $1,7 \%$ & $13,4 \%$ & $100 \%$ \\
\hline Zona Este & $47,1 \%$ & $2,8 \%$ & $1,5 \%$ & $11,5 \%$ & $6,9 \%$ & $7,7 \%$ & $8,7 \%$ & $2,1 \%$ & $11,7 \%$ & $100 \%$ \\
\hline Zona Norte & $46,8 \%$ & $3,9 \%$ & $1,4 \%$ & $9,6 \%$ & $7,1 \%$ & $9,0 \%$ & $10,5 \%$ & $1,9 \%$ & $10,1 \%$ & $100 \%$ \\
\hline Oasis Sur & $48,8 \%$ & $2,2 \%$ & $3,2 \%$ & $12,9 \%$ & $8,6 \%$ & $5,4 \%$ & $5,6 \%$ & $1,6 \%$ & $11,6 \%$ & $100 \%$ \\
\hline Valle de Uco & $56,5 \%$ & $2,6 \%$ & $1,4 \%$ & $10,0 \%$ & $7,9 \%$ & $3,1 \%$ & $6,8 \%$ & $1,4 \%$ & $10,2 \%$ & $100 \%$ \\
\hline promedio & $51,2 \%$ & $3,6 \%$ & $1,5 \%$ & $8,2 \%$ & $6,4 \%$ & $8,0 \%$ & $7,7 \%$ & $1,8 \%$ & $11,7 \%$ & $100 \%$ \\
\hline \multicolumn{11}{|c|}{ Mujeres } \\
\hline Gran Mendoza & $30,2 \%$ & $10,9 \%$ & $0,8 \%$ & $3,6 \%$ & $5,9 \%$ & $13,7 \%$ & $10,2 \%$ & $2,0 \%$ & $22,7 \%$ & $100 \%$ \\
\hline Zona Este & $27,2 \%$ & $5,8 \%$ & $1,8 \%$ & $13,7 \%$ & $11,3 \%$ & $8,7 \%$ & $10,5 \%$ & $2,1 \%$ & $18,9 \%$ & $100 \%$ \\
\hline Zona Norte & $28,0 \%$ & $8,2 \%$ & $1,3 \%$ & $11,3 \%$ & $11,8 \%$ & $10,2 \%$ & $9,4 \%$ & $2,0 \%$ & $17,9 \%$ & $100 \%$ \\
\hline Oasis Sur & $33,2 \%$ & $3,6 \%$ & $3,1 \%$ & $13,9 \%$ & $13,2 \%$ & $6,5 \%$ & $6,9 \%$ & $2,0 \%$ & $17,4 \%$ & $100 \%$ \\
\hline Valle de Uco & $35,4 \%$ & $3,8 \%$ & $2,3 \%$ & $13,9 \%$ & $13,7 \%$ & $3,9 \%$ & $9,3 \%$ & $1,7 \%$ & $16,0 \%$ & $100 \%$ \\
\hline promedio & $31,0 \%$ & $7,3 \%$ & $1,6 \%$ & $9,6 \%$ & $10,0 \%$ & $9,8 \%$ & $9,3 \%$ & $2,0 \%$ & $19,4 \%$ & $100 \%$ \\
\hline
\end{tabular}

Fuente: República Argentina, IV Censo Escolar...,., pp. 430-433.

Si se analizan los datos para cada una de las regiones se observa una marcada homogeneidad con relación a la principal causa de abandono que era el trabajo de los menores. Sin embargo, se observan diferencias sustanciales entre las regiones con la segunda causa de deserción. Mientras que la pobreza tenía una mayor incidencia en el Gran Mendoza, la falta de grados o la distancia a los establecimientos educativos eran más importantes en el

152 Oasis Sur, Valle de Uco y en la región Norte. Por último, llama la atención la variable "otros" -que surge como suma de componentes-, ya que tiene un peso significativo, especialmente en el caso de las mujeres. 
En efecto, el análisis por sexo sugiere que los hombres registran una mayor salida de la escuela por trabajo $(51,2 \%)$ en relación a las mujeres (31 \%). Sin embargo, la segunda causa de deserción entre ellas corresponde a un conjunto de causas que no pueden ser identificadas y que fueron agrupadas en la categoría de "otros", con una importancia relativa que casi duplica a los porcentajes obtenidos para los hombres. Se puede presumir que la deserción escolar en el caso de las mujeres estuvo asociada a tareas relacionadas con el hogar o a la "ayuda familiar" que no eran identificadas como trabajo ni siquiera cuando estas producían aportes monetarios al ingreso total familiar ${ }^{43}$. Más allá de esta diferencia, el resto de las causas de la deserción escolar de los niños mendocinos fueron similares entre hombres y mujeres y, a su vez, entre las diferentes subregiones de la provincia.

Si bien estos datos no alcanzan para comprender el conjunto de factores que operaron en el analfabetismo y la deserción a nivel local, muestran unas tendencias que, aunque fuertemente heterogéneas, mantienen características comunes con el resto de la República. En este sentido, los resultados obtenidos para la provincia de Mendoza en la primera mitad del siglo XX no parecen diferir demasiado de la visión general que se tiene sobre la educación a nivel nacional, pero se han podido encontrar algunos indicios sobre la relación entre analfabetismo, los índices de deserción escolar y el trabajo de los menores, relación que parece haber sido establecida desde tiempos muy remotos en la provincia.

\section{REFLEXIONES FINALES}

Este trabajo ha analizado la evolución de la asistencia escolar y los niveles de analfabetismo a nivel global en la provincia de Mendoza, sus discrepancias entre regiones y género, y los factores asociados a tal fenómeno desde fines del siglo XIX hasta mediados del siglo XX, en el marco de un proceso de políticas públicas que intentó mitigarlo.

43 Esta característica del trabajo femenino, como tareas en el hogar o tareas económicas pero identificadas como "ayuda familiar", aún hoy sigue siendo una característica que se mantiene invisibilizada en la sociedad y solo pude ser visualizada con mediciones o encuestas específicas. 
En particular, se ha intentado identificar las causas del analfabetismo en un grupo social altamente vulnerable como son los menores en general y de los sectores rurales en particular, debido a que sus elecciones se encontraban subordinadas a terceros: padres, tutores o Estado.

En este sentido, a partir del análisis de fuentes secundarias y de los datos que surgen de los censos educativos y de población es posible determinar que más allá de las limitaciones estructurales de falta de escuelas o maestros, las condiciones socioeconómicas y territoriales de los niños condicionaron sus posibilidades de acceso a la educación. Como han dejado plasmado Suárez para la década de 1920 y Olguín para la década de 1930, el trabajo infantil -más recurrente en las zonas rurales que en las urbanasfue una de las condiciones fundamentales de la persistencia de analfabetismo en la provincia, aun cuando este estaba prohibido por la legislación. La falta de control por parte del Estado fue denunciada por estos expertos pero, sin embargo, los aspectos culturales asociados al trabajo familiar parecerían ser preponderantes para el desgranamiento y/o deserción escolar.

A partir de los censos también se ha podido mostrar que los factores estructurales como, por ejemplo, la falta de grados y la distancia al colegio, eran causas de menor importancia frente al problema del trabajo o la pobreza. Se observa, por su parte, una clara diferencia entre los menores de la ciudad capital y el resto de las regiones, ya fuesen estos varones o mujeres, que se corresponde con las visiones de los expertos de las décadas precedentes.

A pesar de todo esto, los niveles de analfabetismo fueron disminuyendo progresivamente en la provincia a lo largo de todo el período bajo análisis, aun cuando las causas asociadas a factores sociales no parecen haber cambiado significativamente. Si algunas de las circunstancias sociales hubiesen cambiado o, como dejaron expresado Olguín y Suárez, si solo se hubiese cumplido con la legislación sobre el trabajo infantil, sería posible pensar que los niveles de analfabetismo hubiesen sido aún menores y el

154 desarrollo de las posibilidades individuales hubiese sido más equitativos entre hombres y mujeres y entre niños del área rural y de las ciudades. Sin lugar a dudas, la "desidia de los funcionarios encargados de hacer cumplir 
la ley y de las autoridades municipales y policiales que tienen en sus manos los elementos conducentes a su aplicación rigurosa" 44 habría contribuido a que los niños tuvieran que realizar primero las actividades de producción y luego asistir a la escuela.

\section{BibLIOGRAFÍA}

Artieda, Teresa. "El magisterio en los territorios nacionales: el caso de Misiones". En La educación en las provincias y territorios nacionales 1885-1945, editado por Adriana Puiggrós. Buenos Aires: Colección Historia de la Educación en la Argentina, Editorial Galerna, 1993.

Ascolani, Adrián. "Historia de la historiografía educacional argentina. Autores y problemas (1910-1990)". En La educación en Argentina. Estudios de historia, editado por Adrián Ascolani. Rosario: Ediciones del Arca, 1999.

Ascolani, Adrián. "La investigación reciente en Historia de la educación argentina. Campo de estudio interdisciplinar y problemáticas actuales" En El sistema educativo en Argentina, editado por Adrián Ascolani (compilador). Rosario: Estudios de historia, Libro Editor, 2010.

Barrio, Patricia y Florencia Rodríguez Vázquez,. "Instituciones, saberes y expertos para un Estado provincial: Leopoldo Suárez, de agrónomo a funcionario itinerante del lencinismo, Mendoza, 1918-1930". Boletín del Instituto de Historia Argentina y Americana "Dr. Emilio Ravignani”, Tercera serie, número 44 (primer semestre 2016).

Barbero, María Inés y Darío Roldán. "Inmigración y educación (18801910). La escuela como agente de integración”. Cuadernos de historia regional, Vol. III, No 9. Buenos Aires: Universidad Nacional de Luján (1987): 72-86.

Bertoni, Lilia Ana. Patriotas, cosmopolitas y nacionalistas. La construcción de la nación argentina a fines del siglo XIX. Buenos Aires: Fondo de Cultura Económica, 2001.

Cerdá, Juan Manuel. Condiciones de vida y vitivinicultura. Mendoza, 18701950. Bernal:, Colección Convergencia, entre Memoria y Sociedad, Editorial Universidad Nacional de Quilmes, 2011.

44 Leopoldo Suárez, El problema..., 20. En este mismo sentido se expresó Dardo Olguín en el apartado "El trabajo de los menores" en el libro de Dardo Olguín, El analfabetismo... 
Cerdá, Juan Manuel. "El trabajo infantil en la agricultura mendocina. Un ejercicio comparativo" En Trabajo agrícola. Una problemática vigente en la Argentina, editado por Juan Manuel Cerdá y Talía Violeta Gutiérrez. Buenos Aires: Editorial CICCUS, 2009.

Cerdá, Juan Manuel. "Mercado de trabajo y condiciones de vida en Mendoza a comienzos del siglo XX". Mundo Agrario. Revista de Estudios Rurales, Vol. 6, N 12 (primer semestre de 2006). Disponible en: http://www.mundoagrario.unlp.edu.ar/article/view/ v06n12a02/1229

Collado, Patricia. "Mendoza, periferia de la periferia próspera. Un análisis sobre el modelo de desarrollo regional", Revista Confluencia, año 1, $\mathrm{N}^{\mathrm{o}} 1$ (invierno 2003).

De la Vega, Jacinto Berardo. Mendoza 1919: ¡Huelga! El nacimiento de la sindicalización del Magisterio mendocino. Mendoza: Ediciones Culturales de Mendoza, 1997.

Feldman, Silvio. "El trabajo de los adolescentes en Argentina. ¿Construyendo futuro o consolidando la postergación social?”. En Adolescencia, pobreza, educación y trabajo, editado por Irene Konterllnik y Cintia Jacinto. Buenos Aires: Losada, 1996, $43-94$.

Filmus, Daniel, Ana Miranda y Julio Zelarayán. "En el mercado de trabajo, ¿el saber no ocupa lugar?: egresados de la escuela media y primer año de inserción laboral". $5^{\text {to }}$ Congreso Nacional de Estudios del Trabajo. Buenos Aires: ASET, 2001.

Fleming, Wiliams. Regional development and transportation in Argentina. Mendoza and the Gran Oeste Argentino Railroad, 1885-1914. New York \& London: Garland Publishing, 1987.

Lacoste, Pablo. El vino del inmigrante: los inmigrantes europeos y la industria vitivinícola argentina: su incidencia en la incorporación, difusión y estandarización del uso de topónimos europeos 1852-1980. Mendoza: Consejo Empresario Mendocino, 2003.

Macri, Mariela, Myriam Ford, Carolina Berliner y María Julia Moltoni. El trabajo infantil no es un juego. Estudios e investigaciones sobre trabajo infanto-adolescente en Argentina (1900-2003). Buenos Aires: Ed. Stella-La Crujía, 2005.

Ministerio de Trabajo, Empleo y Seguridad Social y Organización Internacional del Trabajo. Trabajo infantil y adolescente en cifras. Síntesis de 
la primera encuesta y resultados de la provincia de Mendoza. Buenos Aires: Métis-OIT, 2006.

Olguín, Dardo. El analfabetismo y sus factores. Mendoza: Editorial Best Hnos., 1939.

Organización Internacional del Trabajo. Comunicado de prensa. Programa Internacional para la erradicación del trabajo infantil. Buenos Aires: Editorial IPEC, 2003.

Plotkin, Mariano. "Política, educación y nacionalismo en el Centenario", Todo es Historia, No 221 (1985): 65-80.

Puiggrós, Adriana. La educación en las provincias y territorios nacionales 1885-1945, Colección Historia de la Educación en la Argentina. Buenos Aires: Editorial Galerna, 1993.

Puiggrós, Adriana. Sujetos, disciplina y curriculum, en los orígenes del sistema educativo argentino. Buenos Aires: Editorial Galerna, 1990.

Richard-Jorba, Rodolfo. Poder, economía y espacio en Mendoza. 18501900. Del comercio ganadero a la agroindustria vitivinícola. Mendoza: Editorial de la Universidad Nacional de Cuyo. Facultad de Filosofía y Letras, 1998.

Sanchez, Florencio. M'hijo el doctor. Disponible en http://www.biblioteca.org.ar/libros/70120.pdf

Suárez, Leopoldo. El problema escolar en la provincia. Mendoza: s/d, 1926.

Tedesco, Juan Carlos. Educación y sociedad en la Argentina (1880-1945). Buenos Aires: Ediciones Solar, 1986.

Teobaldo, Mirta. "Estado y sociedad civil en la conformación y desarrollo del sistema educativo del Territorio Nacional de Río Negro". En La educación en las provincias y territorios nacionales 1885-1945, editado por Adriana Puiggrós. Buenos Aires: Editorial Galerna, 1993.

Teobaldo, Mirta. "Enseñar y aprender en las escuelas de la Patagonia Norte (1884-1957)" VIII Congreso Iberoamericano de Historia de la Educación Latinoamericana. Buenos Aires, octubre-noviembre 2008.

\section{Fuentes}

Censos Nacionales de Población correspondientes a los años 1895, 1914 y 1947.

Censo Provincial de Población de 1909. 
Constitución Nacional de la República Argentina.

Provincia de Mendoza. Anuario estadístico Mendoza. Direccion general de Estadistica de la provincia de Mendoza varios años

República Argentina, IV Censo Escolar de la Nación. Correspondiente a 1943, Buenos Aires, 1947.

Para citar este artículo: Cerdá, Juan Manuel. "Las desigualdades edu158 cativas en Mendoza en la primera mitad del siglo XX", Historia Caribe Vol. XII No. 31 (Julio-Diciembre 2017): 127-158. DOI: http://dx.doi. org/10.15648/hc.31.2017.5 